\title{
Mass spectrometric characterization of cyclic dinucleotides (CDNs) in vivo
}

\author{
Andrea Annibal $^{1}$ (i) $\cdot$ Roberto Ripa $^{1} \cdot$ Eugen Ballhysa $^{1,2} \cdot$ Christian Latza $^{1} \cdot$ Nadine Hochhard $^{1} \cdot$ Adam Antebi $^{1,2}$
}

Received: 1 June 2021 / Revised: 10 August 2021 / Accepted: 19 August 2021 / Published online: 2 September 2021

(C) The Author(s) 2021

\begin{abstract}
Cyclic dinucleotides (CDNs) are key secondary messenger molecules produced by cyclic dinucleotide synthases that trigger various cellular signaling cascades from bacteria to vertebrates. In mammals, cyclic GMP-AMP synthase (cGAS) has been shown to bind to intracellular DNA and catalyze the production of the dinucleotide $2^{\prime} 3^{\prime}$ cGAMP, which signals downstream effectors to regulate immune function, interferon signaling, and the antiviral response. Despite the importance of CDNs, sensitive and accurate methods to measure their levels in vivo are lacking. Here, we report a novel LC-MS/MS method to quantify CDNs in vivo. We characterized the mass spectrometric behavior of four different biologically relevant CDNs (c-di-AMP, c-di-GMP, $3^{\prime}$ $3^{\prime}$ cGAMP, $2^{\prime} 3^{\prime}$ cGAMP) and provided a means of visually representing fragmentation resulting from collision-induced dissociation at different energies using collision energy breakdown graphs. We then validated the method and quantified CDNs in two in vivo systems, the bacteria Escherichia coli OP50 and the killifish Nothobranchius furzeri. We found that optimization of LCMS/MS parameters is crucial to sensitivity and accuracy. These technical advances should help illuminate physiological and pathological roles of these CDNs in in vivo settings.
\end{abstract}

Keywords 2'3' cGAMP $\cdot$ Nothobranchius furzeri $\cdot$ Mass spectrometry $\cdot$ cGAS

\section{Introduction}

Cyclic dinucleotides (CDNs) are a class of molecules that serve as important secondary messengers conserved across taxa. Bacterial CDNs form through the cyclization of two nucleotides via a phosphodiester bond that links the $\mathrm{C} 3^{\prime}$ of one pentose ring with the $\mathrm{C}^{\prime}$ of the other nucleotide, resulting in a $3^{\prime} 5^{\prime}$ cyclic dinucleotide. Dinucleotide cyclase vibrio (DncV)-like nucleotidyl transferases (CDNTases) catalyze such reactions in prokaryotes and are best known for the synthesis of purine cyclic-bis dimeric GMP and c-di-AMP, heterocyclic 3'3' cGMP-AMP (cGAMP), but have been recently shown to generate pyrimidine derivatives as well [1]. These

Andrea Annibal

aannibal@age.mpg.de

Adam Antebi

aantebi@age.mpg.de

Max Planck Institute for Biology of Ageing, Cologne, Germany

2 Cologne Excellence Cluster on Cellular Stress Responses in Aging-Associated Diseases (CECAD), University of Cologne, Cologne, Germany molecules regulate processes as diverse as potassium ion channel expression, osmoprotection, cell-wall homeostasis, DNA repair, and antibiotic resistance [2, 3]. Most notably, cdi-GMP was identified as playing a central role in biofilm production, whereas $3^{\prime} 3^{\prime}$ cGAMP modulates bacterial chemotaxis and protects against viral infection $[1,4-6]$.

Vertebrate cyclic GMP-AMP synthase (cGAS) is best known for its role in nucleic acid signaling. In particular, it senses both foreign and cytosolically mislocalized selfdouble-stranded (ds)DNA and triggers a defense response $[7,8]$. Upon binding dsDNA, cGAS generates a unique $2^{\prime} 3^{\prime}$ cGAMP isomer, which activates the endoplasmic reticulum resident receptor Stimulator of Interferon Genes (STING) [9]. STING itself responds to either endogenous or bacterially produced CDNs, and translocates to the Golgi, where it interacts with TBK1 kinase to induce IRF3-dependent type I interferon and NF-KB transcriptional responses, thereby mounting antiviral immunity and antimicrobial defense [10]. Recent work also suggests that cGAS/STING signaling is involved in sensing retroviruses, including HIV-1 and HIV-2, as well as the RNA virus COVID-19 [11, 12]. Further, aberrant activation of the pathway, triggered by the presence of intracellular chromatin micronuclei or mitochondrial DNA, is also related 
to chronic inflammation, cancer, and cellular senescence [13-15]. Thus, the cGAS/Sting pathway has emerged as central to nucleic acid dynamics, immunity, and aging.

Despite significant advances in elucidating the physiology of the cGAS/STING pathway, methods to monitor CDNs' dynamics in living organisms remain limited. Most studies rely on comparative measurement of downstream components, such as type I interferons (IFN-I) and IFN stimulated genes (ISGs) as indirect indicators of cGAS activity. Measurement of the CDNs themselves has been quantified by competitive ELISA [9], monoclonal antibodies, thin-layer chromatography, radioisotope, ion-exchange chromatography [16-19], and an RNA-based fluorescent biosensor [20]. However, most of these methods fall short on accuracy, sensitivity, or specificity.

Liquid chromatography-mass spectrometry (LC-MS) is another method used to measure endogenous cell or tissue cGAMP levels. Work of Lorenzetti et al. and Pajio et al. described a LC-MS-based methodology for the detection of these species in biological samples [21, 22]. Nonetheless, these LC-MS studies lack a structural mass spectrometric characterization of the CDNs, which is the key to develop more sensitive and accurate methods for their quantification.

In this work, we initiated a mass spectrometry-based investigation of four CDNs and optimized an LC-MS/ MS method for their quantification. We performed a quantitative comparison of ion intensities in tandem mass spectra and analysis of energy-dependent (or energy-resolved) curves for structure analysis. These optimized parameters were used to develop a new MRM method, which was validated by quantifying CDNs in the bacteria Escherichia coli OP50. Moreover, we quantified 2'3' cGAMP in tissues of the killifish Nothobranchius furzeri, an important emerging vertebrate model organism for studying aging and disease. These advances should greatly facilitate the accurate and sensitive quantification of cyclic dinucleotides in in vivo settings.

\section{Material and methods}

Chemicals UHPLC-grade water, formic acid, and UHPLCgrade acetonitrile were purchased from Biosolve Valkenswaard, Netherlands. Chloroform was purchased from Merck KGaA (Darmstadt, Germany). UHPLC-grade methanol and 2'3' cGAMP sodium salt (SML1229), 3'3' cGAMP sodium salt (SML1232), c-di-AMP sodium salt (SML1231), c-di-GMP sodium salt (SML1228), adenosine- ${ }^{13} \mathrm{C}_{10},{ }^{15} \mathrm{~N}_{5}-5^{\prime}$ monophosphate lithium salt (650676), Tris hydrochloride, $\mathrm{NaOH}, \mathrm{KCl}$, ethylenediaminetetraacetic acid (EDTA), and tricaine methanesulfonate were purchased from SigmaAldrich, GmbH.
Bacteria culture $E$. coli $\mathrm{OP} 50$ bacteria were grown overnight $(18 \mathrm{~h})$ in LB media composed of $10 \mathrm{~g} / \mathrm{L}$ Bacto tryptone (Sigma 95,039), $5 \mathrm{~g} / \mathrm{L}$ Bacto yeast extract (BD 212720), and $5 \mathrm{~g} / \mathrm{L} \mathrm{NaCl}$. Bacteria were centrifuged for $30 \mathrm{~min}$ at 4000 relative centrifugal force (rcf) at $4{ }^{\circ} \mathrm{C}$. Pellets were frozen in liquid nitrogen and stored at $-80^{\circ} \mathrm{C}$.

Killifish husbandry and tissue extraction All experiments were performed using the killifish strain GRZ-AD [23]. All fish were individually housed in single $2.8-\mathrm{L}$ tanks connected to a water recirculation system receiving $12 \mathrm{~h}$ of light and $12 \mathrm{~h}$ of darkness every day. Temperature was maintained at $27.5^{\circ} \mathrm{C}$. Adult killifish were fed twice a day with $1.1 \mathrm{~mm}$ pellet (BioMar) and brine shrimps (Artemia). For tissue collection, fish were euthanized with an overdose of tricaine methanesulfonate (TMS, MS-222) $(0.4 \mathrm{mg} / \mathrm{mL})$. Liver and gut tissues were immediately extracted by dissection, frozen in liquid nitrogen, and stored at $-80^{\circ} \mathrm{C}$.

Fish transgenesis and genotyping To generate the $\mathrm{CGAS}^{-/-}$ fish line, we used CRISPR/Cas9 genome engineering, targeting the conserved cGAS DNA-binding region with guide RNAs using the algorithm CHOPCHOP (https:// chopchop.cbu.uib.no/). One-cell-stage killifish embryos were injected with $\sim 2-3 \mathrm{~nL}$ of a solution containing $200 \mathrm{ng} / \mu \mathrm{L}$ of Cas 9 protein (IDT: 1081060), $20 \mathrm{ng} / \mu \mathrm{L}$ of sgRNA (IDT: AltR ${ }^{\circledR}$ CRISPR-Cas9 sgRNA, target specific sequence: GCATTGAAACGTGATCCAAC), $200 \mathrm{mM} \mathrm{KCl}$, and $10 \%$ $(\mathrm{v} / \mathrm{v})$ red-phenol. Juvenile fish ( 3 weeks old) were genotyped by fin clipping. The tissue samples were first digested for $1 \mathrm{~h}$ at $98{ }^{\circ} \mathrm{C}$ in alkaline buffer $(\mathrm{NaOH} 25 \mathrm{mM}$, EDTA 0 . $2 \mathrm{mM}$ ) under constant shaking, and then 1 volume of Tris- $\mathrm{HCl}$ buffer ( $\mathrm{pH}$ 5.5) was added to rebalance the $\mathrm{pH}$. One microliter of solution was used as a template for a standard $25-\mu \mathrm{L}$ PCR (DreamTaq Green PCR Master Mix, ThermoFisher) using the forward (Fw: GTTAAGGAACCCCTTCGCACT) and reverse (Rw: TTGCCGTCATCTCCCATTCTG) primers corresponding to the cGAS gene. The PCR products (554 bp) were purified from an agarose gel and sequenced (Supplementary Figs. 1, 2).

Cyclic dinucleotide extraction CDNs were extracted from bacteria and from killifish by modification of our previous protocols $[24,25]$ (Scheme 1). Frozen tissues and bacteria pellets underwent up to three freeze/thaw cycles in liquid nitrogen and were then homogenized by bead beatings for $20 \mathrm{~min}$ at 50 oscillations $/ \mathrm{s}$ at $4{ }^{\circ} \mathrm{C}$ using the Qiagen tissue lyser. Protein concentration was measured with the BCA kit (23225, ThermoFisher). Prior to extraction, $5 \mathrm{ng}$ of an internal standard (adenosine $-{ }^{13} \mathrm{C}_{10},{ }^{15} \mathrm{~N}_{5}-5^{\prime}$-monophosphate) was added. A volume corresponding to $300 \mu \mathrm{g}$ of protein was subjected to Bligh and Dyer extraction by adding $100 \mu \mathrm{L}$ chloroform/ methanol 2:1 v/v. Samples were rotated for $1 \mathrm{~h}$ at $4{ }^{\circ} \mathrm{C}$ and 
a
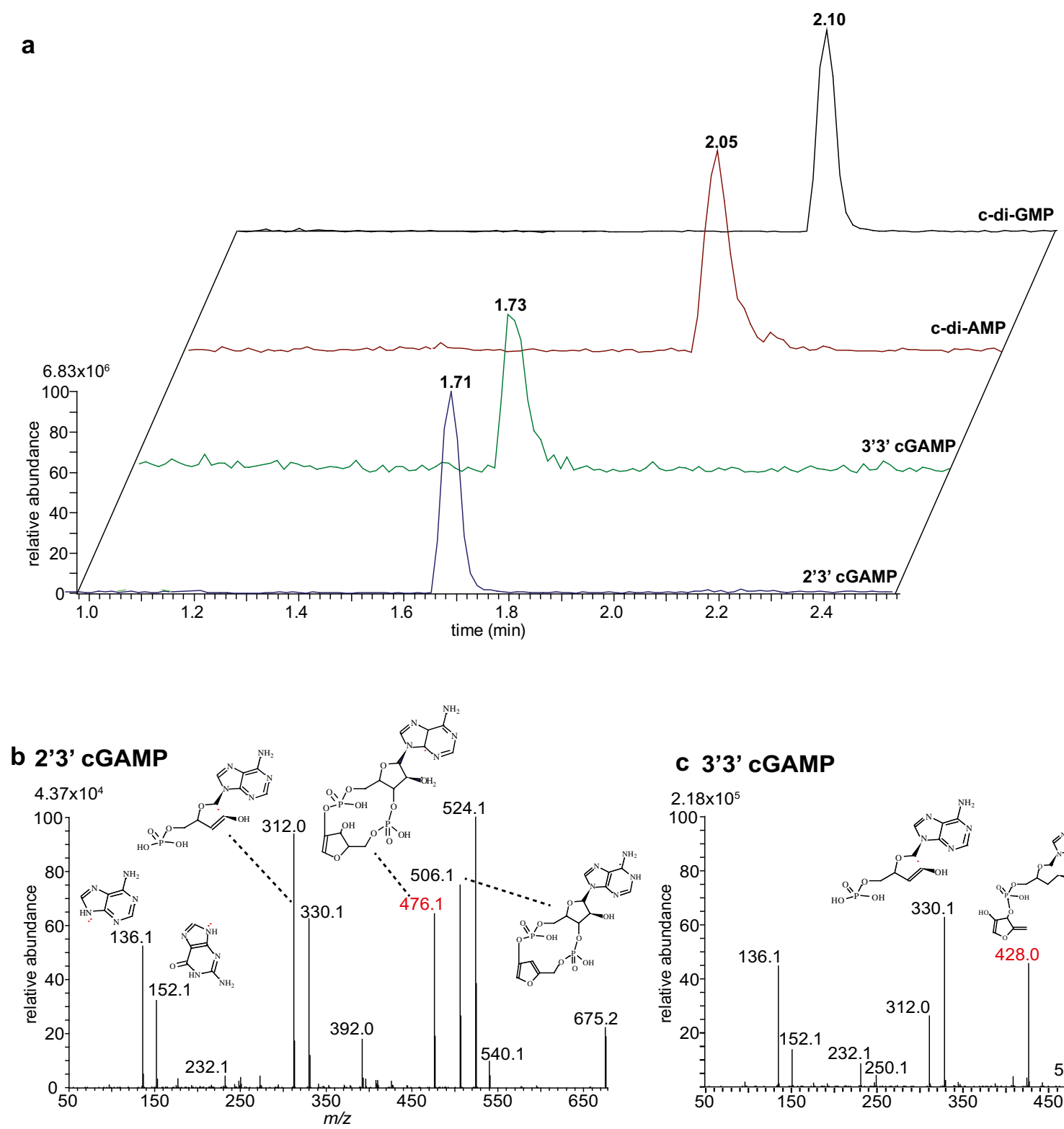

C 3'3' cGAMP

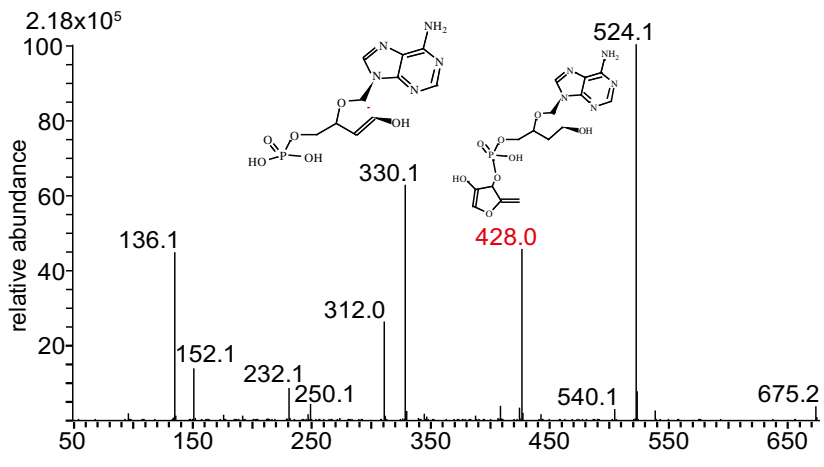

\section{d c-di-AMP}

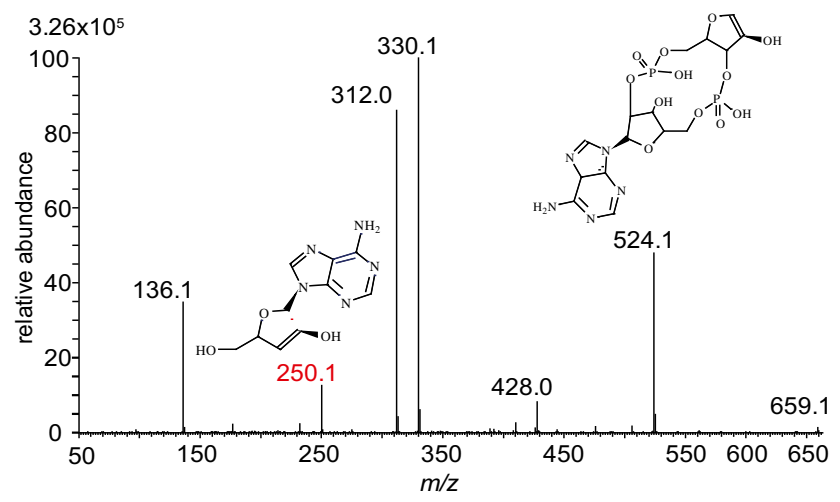

Fig. 1 Characterization of CDNs by LC-MS/MS. a Extracted ion chromatograms (EIC) of CDN standards at concentration $100 \mathrm{nmol} / \mathrm{L}$ analyzed by LC-MS (full scan). Tandem mass spectra of $2^{\prime} 3^{\prime}$ cGAMP

\section{e c-di-GMP}

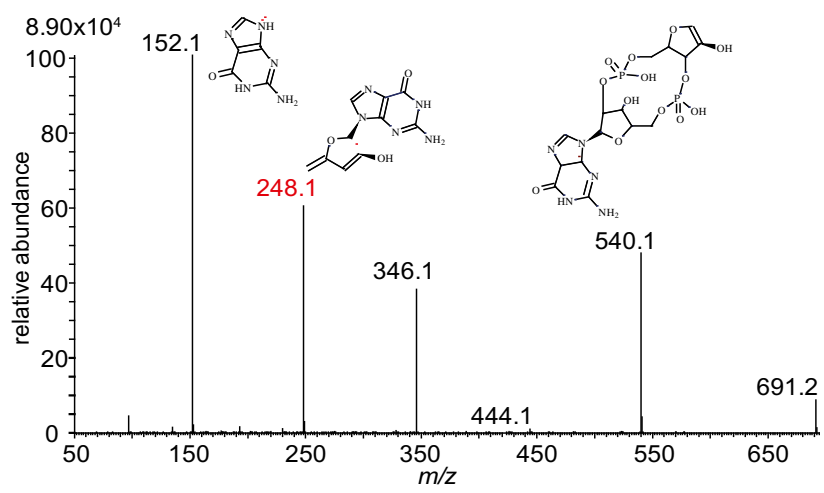

(b), 3'3' cGAMP (c), c-di AMP (d), and c-di-GMP (e), using $30 \mathrm{~V}$ CE. Fragments used for the LC-MS/MS quantification are highlighted in red. The proposed fragments are designated as neutral molecules 


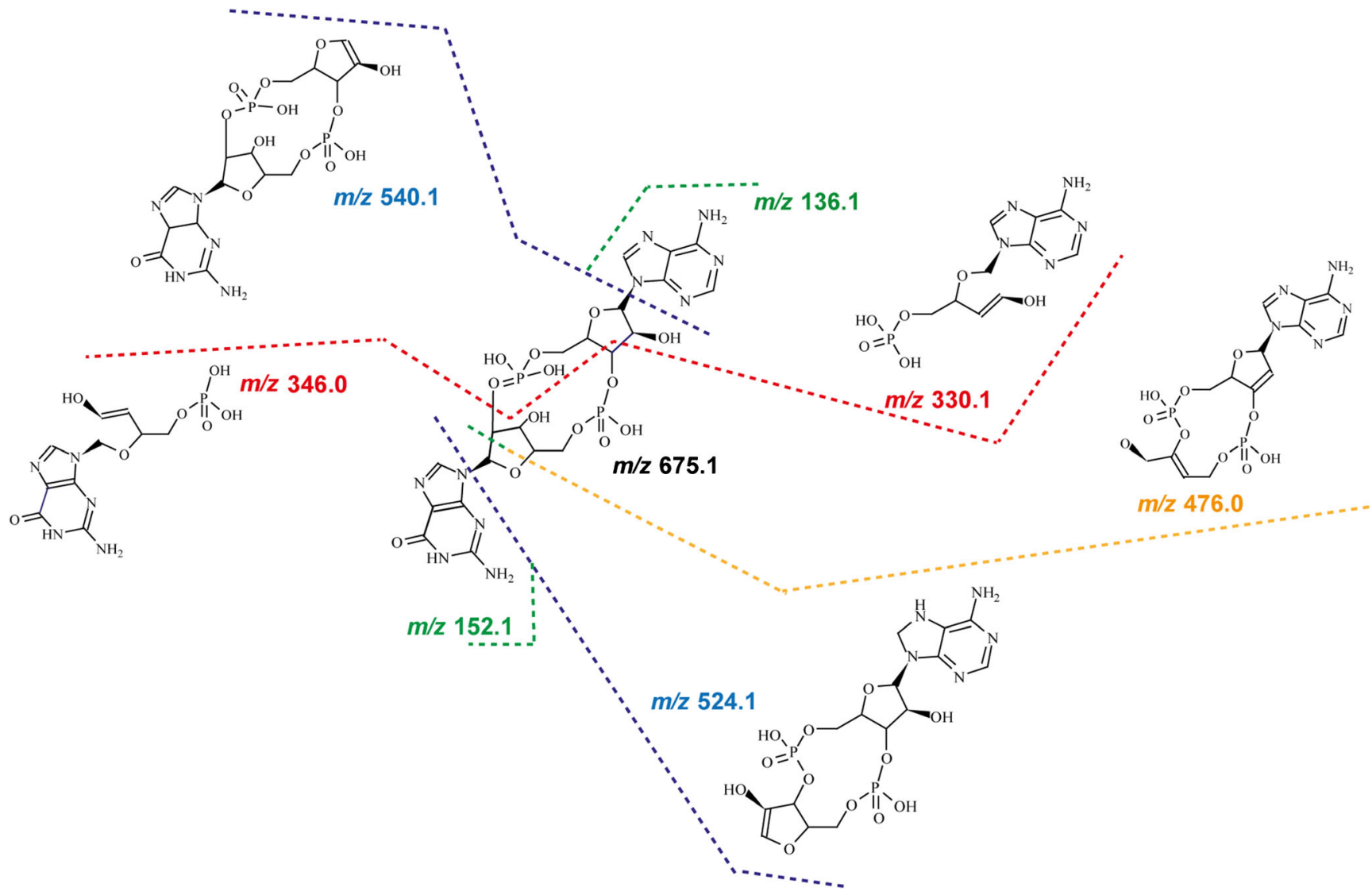

Fig. 2 Fragmentation pattern of CDNs. Several preferential bond breakages occur, including cleavage between the sugar moiety and the nucleobase (green and blue), at the sugar ring (orange), and at the corresponding $\mathrm{C}^{\prime}{ }^{\prime}$ of the pentose ring with the $\mathrm{C}^{\prime}$ of the phosphate group (red). The proposed fragments are designated as neutral molecules centrifuged for $10 \mathrm{~min}$ at $10.000 \mathrm{rpm}$. The supernatant was transferred to a new tube and dried under a Speedvac. Samples were resuspended in $20 \mu \mathrm{L}$ of $1 \% \mathrm{v} / \mathrm{v}$ acetonitrile in water with $0.1 \% \mathrm{v} / \mathrm{v}$ formic acid. Five microliters of the sample was injected into the LC-MS/MS system.

LC-MS/MS instrumentation and conditions Identification and relative quantification of cyclic dinucleotides were performed on a triple quadrupole mass spectrometer (QqQMS) (TSQ Altis, ThermoFisher Scientific GmbH, Bremen, Germany). Standards were dissolved in water and separated by reversephase column (XSelect HSS T3 $2.5 \mu \mathrm{m} 2.1 \times 100 \mathrm{~mm}$, Waters) using a binary pump system (Vanquish, ThermoFisher Scientific GmbH, Bremen, Germany) with solvent $\mathrm{A}$ as water with $0.1 \% \mathrm{v} / \mathrm{v}$ formic acid and eluent $\mathrm{B}$ as acetonitrile with $0.1 \% \mathrm{v} / \mathrm{v}$ formic acid, using a gradient modified from previous work [21].

Briefly, the gradient began with $1 \%$ eluent $\mathrm{B}$ and ramped up to $5 \%$ in $30 \mathrm{~s}$. The gradient increased up to $50 \%$ eluent B in 5 min and reached $60 \%$ eluent $\mathrm{B}$ in 1 additional minute. At $7 \mathrm{~min}$, it reached $90 \%$ eluent B and was held for $2 \mathrm{~min}$. The gradient then decreased to $20 \%$ eluent B in 5 min and was held for $2 \mathrm{~min}$ at $1 \%$ eluent $\mathrm{B}$. The total time was $16 \mathrm{~min}$. The flow rate was $0.2 \mathrm{~mL} / \mathrm{min}$. The column temperature was set at $30{ }^{\circ} \mathrm{C}$ and the auto sampler temperature was set to $4{ }^{\circ} \mathrm{C}$. Data was analyzed using Xcalibur version 4.0 and Trace Finder version 4.1 .

ESI-MS/MS conditions ESI ionization parameters were as follows: $3.5 \mathrm{kV}, 25$ a.u. sheath gas, 5 a.u. auxiliary, and $350{ }^{\circ} \mathrm{C}$ transfer ion capillary. All the spectra were acquired in positive ion mode.

Full scans were acquired from 150 to $900 \mathrm{~m} / \mathrm{z}$ with a scan rate of $1000 \mathrm{Da} / \mathrm{s}$ using a resolution of Q1 of $0.7 \mathrm{~m} / z$. The product ion scans were obtained for each individual precursor using a scan rate of $1000 \mathrm{Da} / \mathrm{s}$, using Q1 resolution of $0.7 \mathrm{~m} / \mathrm{z}$ and Q3 resolution of $0.7 \mathrm{~m} / \mathrm{z}$. Tandem mass spectra were obtained by CID, using argon set at 1.5 mTorr with collision energy between 0 and $50 \mathrm{~V}$. Multiple reaction monitoring (MRM) measurements using ESI-MS/MS were achieved with the following parameters: Q1 resolution $0.7 \mathrm{~m} / \mathrm{z}$ and Q3 resolution $1.2 \mathrm{~m} / \mathrm{z}$. Different collision energies were used for each compound as indicated in the main text. Unique combinations of Q1 and Q3 $\mathrm{m} / \mathrm{z}$, values were used to quantify cyclic 
Scheme 1 Molecular structure of four main cyclic dinucleotides (CDNs) produced in bacteria and vertebrates
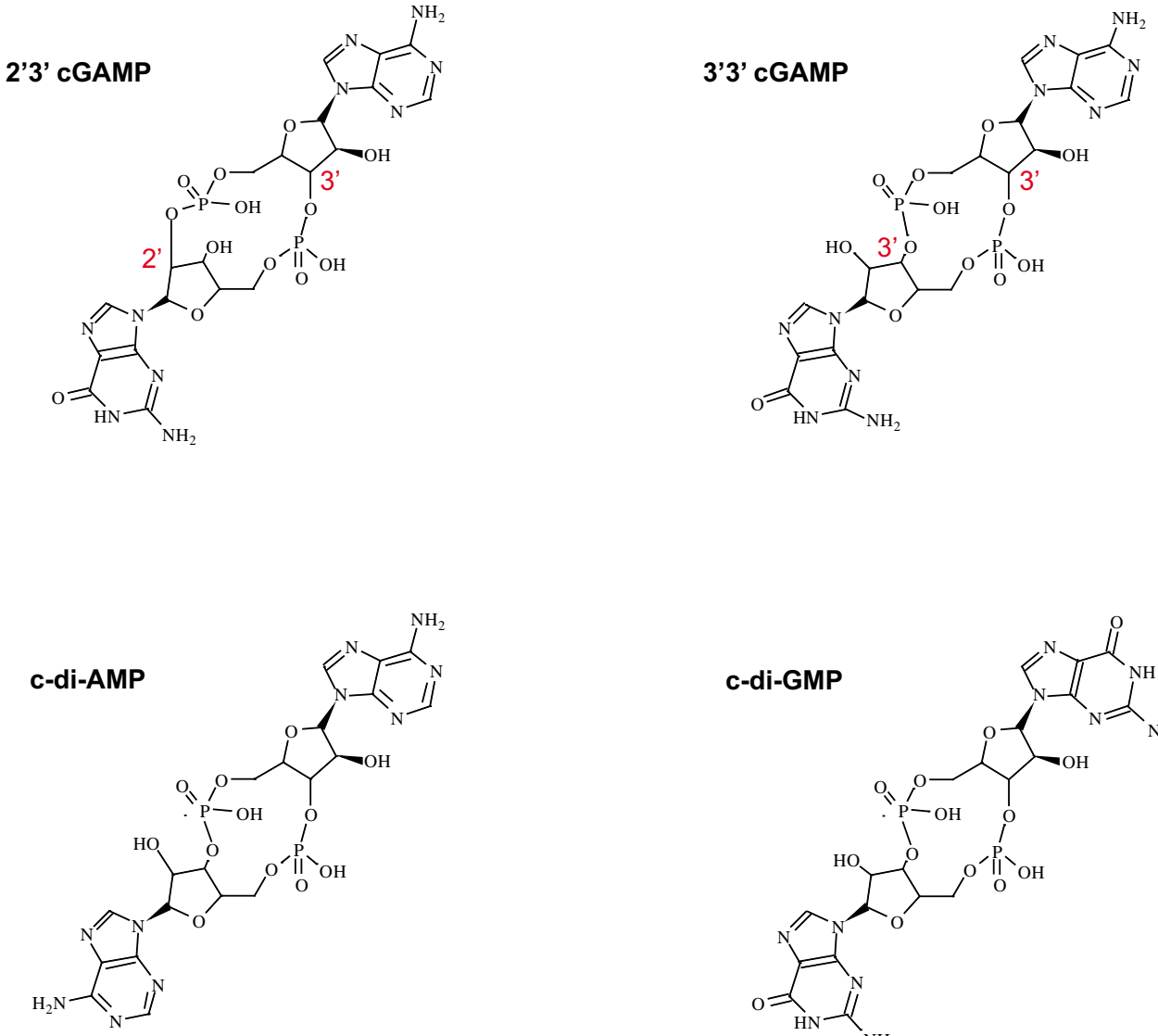

dinucleotides (see main text). The relative response for each cyclic dinucleotide was calculated by dividing the peak area of the analyte to the internal standard peak area (adenosine- ${ }^{13} \mathrm{C}_{10},{ }^{15} \mathrm{~N}_{5}-5^{\prime}$-monophosphate, $\mathrm{m} / \mathrm{z}, 407.08$ ) and further normalized to protein concentration. The internal standard was used to compensate for variability in signal intensity due to ion suppression caused by matrix components that may influence the efficiency of ionization.

Statistical analysis GraphPad Prism Version 7.0c software was used for graphics and statistical testing.

\section{Results}

We employed UHPLC coupled with ESI-MS/MS for the investigation of cyclic dinucleotides in vivo (Scheme 1). We first characterized the resolution of authentic standards of CDN molecular species via reversed-phase liquid chromatography using full scan acquisition (Fig. 1). Single protonated ions $[\mathrm{M}+\mathrm{H}]^{+}$were chosen for the analysis. Both heterocyclic isomers, 2' 3 ' cGAMP and 3'3' cGAMP, displayed mono protonated ions at $\mathrm{m} / \mathrm{z}, 675.1$ with a retention time of $1.71 \mathrm{~min}$ and of $1.73 \mathrm{~min}$, respectively (Fig. 1a). Cyclic-di-AMP and c-diGMP showed single protonated ions at $m / z 659.1$ and 691.2 and eluted at $2.05 \mathrm{~min}$ for c-di-AMP and $2.10 \mathrm{~min}$ for c-diGMP. Despite their co-elution, it was still possible to distinguish c-di-AMP from c-di-GMP due to their different $\mathrm{m} / \mathrm{z}$ values. Nonetheless, in order to discriminate between $2^{\prime} 3^{\prime}$ and $3^{\prime} 3^{\prime}$ cGAMP, we performed product ion scan experiments to retrieve unique fragments for each compound.

Product ion scans of the four different CDNs were initially performed using the same collision energy ( $30 \mathrm{~V})$ (Fig. 1b-e). The tandem mass spectra obtained by collision-induced dissociation (CID) of 2'3' cGAMP exhibited several dominant daughter ions (Fig. 1a). The ion at $\mathrm{m} / \mathrm{z} 540.1$ was assigned to $\mathrm{C}_{15} \mathrm{H}_{20} \mathrm{~N}_{5} \mathrm{O}_{13} \mathrm{P}_{2}{ }^{+}$, whereas the ion at $\mathrm{m} / z 524.1$ corresponded to $\mathrm{C}_{15} \mathrm{H}_{20} \mathrm{~N}_{5} \mathrm{O}_{12} \mathrm{P}_{2}$, ${ }^{+}$and, by subsequent water loss, led to the formation of the ion at $\mathrm{m} / \mathrm{z} 506.1$. The ion at $\mathrm{m} / \mathrm{z}$ 476.1 corresponded to $\mathrm{C}_{14} \mathrm{H}_{16} \mathrm{~N}_{5} \mathrm{O}_{10} \mathrm{P}_{2}{ }^{+}$, and the ion at $\mathrm{m} / \mathrm{z}$ 
330.1 was assigned to $\mathrm{C}_{10} \mathrm{H}_{13} \mathrm{~N}_{5} \mathrm{O}_{6} \mathrm{P}^{+}$. Water loss from the latter ion led to a product ion at $\mathrm{m} / \mathrm{z} 312.0$. The tandem mass spectra of $\mathrm{C}_{10} \mathrm{H}_{13} \mathrm{~N}_{5} \mathrm{O}_{6} \mathrm{P}^{+}$resulted in the appearance of ion at $m / z, 152.1\left(\mathrm{C}_{5} \mathrm{H}_{6} \mathrm{~N}_{5} \mathrm{O}^{+}\right)$and $m / z, 136.1\left(\mathrm{C}_{5} \mathrm{H}_{6} \mathrm{~N}_{5}{ }^{+}\right)$, which belong respectively to the nucleobases, guanine and adenine.

The product ion spectra of $3^{\prime} 3^{\prime}$ cGAMP were similar to that of 2'3' cGAMP (Fig. 1c). The ion at $\mathrm{m} / \mathrm{z} 524.1$ $\left(\mathrm{C}_{15} \mathrm{H}_{20} \mathrm{~N}_{5} \mathrm{O}_{12} \mathrm{P}_{2}^{+}\right)$was also present in the spectra as well as the ion pair at $m / z, 330.1$ and 312.0. These product ion spectra also contained unique fragments, such as the ion at $\mathrm{m} / \mathrm{z} 428.0$ $\left(\mathrm{C}_{15} \mathrm{H}_{19} \mathrm{~N}_{5} \mathrm{O}_{8} \mathrm{P}^{+}\right)$, which was absent in the $2^{\prime} 3^{\prime}$ cGAMP tandem mass spectra. These data indicate that each of the two isomers has specific marker ions that can be used to distinguish the two molecular species.

The tandem mass spectra of c-di-AMP were dominated by the presence of the ion at $m / z 524.1\left(\mathrm{C}_{15} \mathrm{H}_{20} \mathrm{~N}_{5} \mathrm{O}_{12} \mathrm{P}_{2}^{+}\right)$, and the ions at $\mathrm{m} / \mathrm{z} 330.1$ and $\mathrm{m} / \mathrm{z} 312.0$ (Fig. 1d). The product ion at $m / z 250.10$ was assigned to $\mathrm{C}_{10} \mathrm{H}_{12} \mathrm{~N}_{5} \mathrm{O}_{3}{ }^{+}$. As expected, the tandem mass spectra displayed only a single ion at $\mathrm{m} / \mathrm{z}, 136.1$ as both of the nucleotide moieties are adenosine.

The product ion scan of c-di-GMP revealed fewer fragments in comparison to other CDNs (Fig. 1e). We could identify the product ion at $m / z 540.1$ and the ion at $m / z 346.1$. This CID spectra displayed a unique fragment for c-di-GMP, namely at $m / z 248.1$, which corresponded to $\mathrm{C}_{10} \mathrm{H}_{10} \mathrm{~N}_{5} \mathrm{O}_{3}{ }^{+}$. The ion at $\mathrm{m} / \mathrm{z} 152.1$ was present only in this tandem mass spectra, and assigned to guanine.

In sum, the analysis of the four product scans allowed us to identify specific fragmentation patterns of CDNs upon CID (Fig. 2), with three main sites for breakage. The first cleavage occurs at the bond between the nucleobase and the ribose moiety. By loss of the nucleobase, two ion pairs are formed, 152.1/524.1 by loss of guanine and 136.1/540.1 by loss of adenine. The second ion pair is generated by cleavage at two bonds: between the $\mathrm{C}^{\prime}$ ' of the pentose ring with the $\mathrm{C}^{\prime}$ bond of the other nucleotide, and between the $\mathrm{C}^{\prime}$ ribose ring and the $\mathrm{C}^{\prime}$ ' of the second nucleotide. This breakage leads to ring opening, giving rise to the ions at $\mathrm{m} / \mathrm{z} 330.1$ and at $m / z 346.0$.

Remarkably, we observed breakage of a third bond, which occurred only at the sugar moiety of guanosine, leading to the formation of the fragment ion at $\mathrm{m} / \mathrm{z}$ 476.0. In none of the MS/MS spectra were we able to detect the counterpart ion for breakage of the adenosine sugar moiety (expected ion at $\mathrm{m} / \mathrm{z}, 492.1$ ).

Examining various energy-resolved curves provides a simple and valuable approach to select the best transition for multiple reaction monitoring (MRM). To optimize detection, we therefore examined the collision energy (CE)-breakdown curves (or energy resolved) of the four CDNs, retrieving fragment ions that might differentiate the isomers (Fig. 3). We plotted the intensity of the fragment ions upon varying the $\mathrm{CE}$ over a range of $0-50 \mathrm{~V}$.
The breakdown curves for $2^{\prime} 3^{\prime}$ cGAMP revealed that most of the product ions reached a peak at $\mathrm{CE}$ of $30 \mathrm{~V}$, which then decreased at higher voltages (Fig. 3a). As expected, the intensity of the precursor ion inversely decreased, reaching zero intensity at CE of $30 \mathrm{~V}$.

The breakdown curves for $3^{\prime} 3^{\prime}$ cGAMP exhibited a different CE profile. The intensity of the fragment ions $\mathrm{m} / \mathrm{z}, 136.1$ and 312.0 increased at $\mathrm{CE}$ of $30 \mathrm{~V}$, but increased even further at higher voltages of 40 and $50 \mathrm{~V}$ (Fig. 3b). The intensity of the ion at $m / z 428.0$ also increased at higher voltages (Fig. 3c). Thus, 2'3' cGAMP and 3'3' cGAMP positional isomers can be additionally differentiated by their CE-breakdown curves.

CE-breakdown curves for c-di-AMP and c-di-GMP revealed different profiles compared to the heterocyclic molecules. In both curves, the daughter ions reached a peak at $\mathrm{CE}$ of $20 \mathrm{~V}$. The CE curve of c-di-AMP showed a slower decrease for the ions 330.1 and 136.1 , from $\mathrm{CE}$ at $20 \mathrm{~V}$ to $\mathrm{CE}$ at $40 \mathrm{~V}$ (Fig. 3d). The ion at $m / z 250.1$ had a maximum intensity at CE of $20 \mathrm{~V}$ and slowly decreased at higher CE (Fig. 3e).

The CE curve profile of c-di-GMP for the fragment ion at $\mathrm{m} / \mathrm{z}, 248.1$ increased at $\mathrm{CE}$ of $10 \mathrm{~V}$ with a maximum at $\mathrm{CE}$ of $20 \mathrm{~V}$, then rapidly decreased at higher voltage (Fig. 3d). The ions at $\mathrm{m} / \mathrm{z} 540.1$ and 152.1 also increased at CE of $20-30 \mathrm{~V}$ and decreased at CE of $40 \mathrm{~V}$.

Based on the CE-breakdown curves, we selected the optimal collision energy at the maximum intensity of the fragment ion curve and the minimum of the precursor ion curve. Hence, we used a collision energy of $30 \mathrm{~V}$ for $2^{\prime} 3^{\prime}$ cGAMP and $3^{\prime} 3^{\prime}$ cGAMP, and $20 \mathrm{~V}$ for c-diAMP and c-di-GMP. Furthermore, unique fragments were chosen for each compound. We selected fragment ion at $m / z, 476.01$ for $2^{\prime} 3^{\prime}$ cGAMP, ion at $\mathrm{m} / \mathrm{z}$ 428.0 for $3^{\prime} 3^{\prime}$ cGAMP, ion at $\mathrm{m} / \mathrm{z} 250.1$ for c-di-AMP, and ion at $m / z 248.1$ for c-di-GMP. Thus, using the above optimized parameters, we created a new MRM-based method (LC-MS/MS) to distinguish these moieties.

Limits of detection (LOD) and quantification (LOQ) were determined from serial dilutions of the seven standards ranging from $10 \mathrm{pg} / \mathrm{mL}$ to $10 \mathrm{ng} / \mathrm{mL}$ (Tables 1 and 2). All external calibration curves exhibited high levels of linearity $(>0.90)$. Further, this method resulted in high intraday (5-9\%) and interday precision (8-12\%) for LC-MS/MS. Standards were also spiked into killifish samples prior to liquid-liquid extraction to calculate the recovery rate, which exceeded $83 \%$.

In order to test the validity of the method, we used the optimized LC-MS/MS MRM parameters to quantify CDNs in biological samples. We first quantified endogenous $3^{\prime} 3^{\prime}$ cGAMP, c-di-AMP, and c-di-GMP from extracts of the bacteria $E$. coli (OP50 strain). The spectra clearly showed the presence of these three CDNs (Fig. 4a) within complex mixtures. The relative quantification of these species revealed higher levels of c-di-GMP and 3',3' cGAMP in comparison to the c-di-AMP. As expected, the $2^{\prime} 3^{\prime}$ cGAMP isomer was absent (Fig. 4b). 


\section{a 2'3' cGAMP}

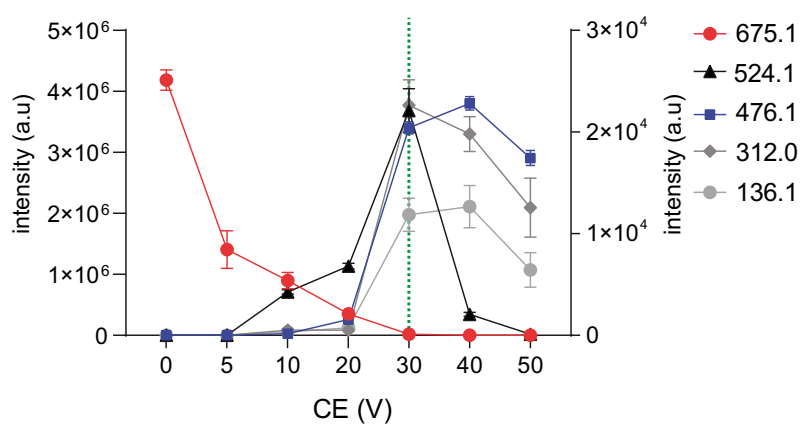

\section{b 3'3' cGAMP}

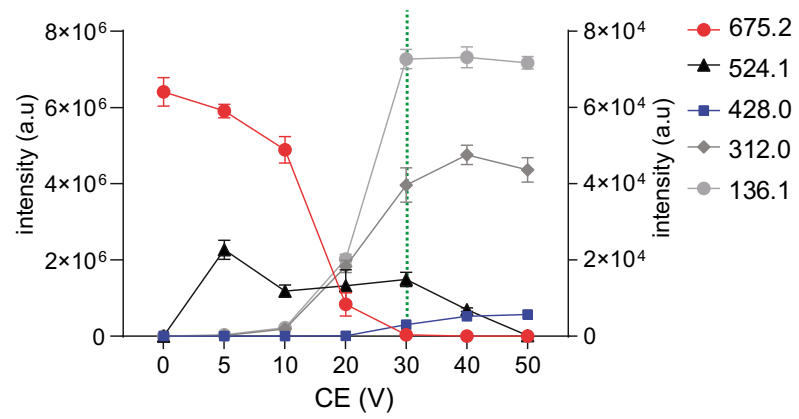

C

\section{d c-di-AMP}

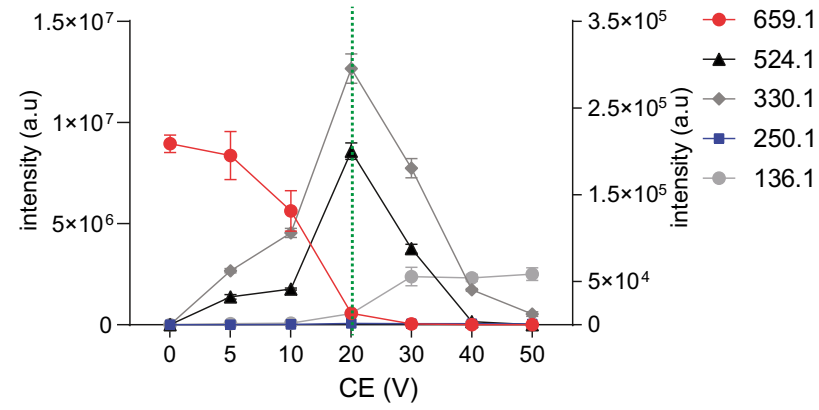

\section{f c-di-GMP}

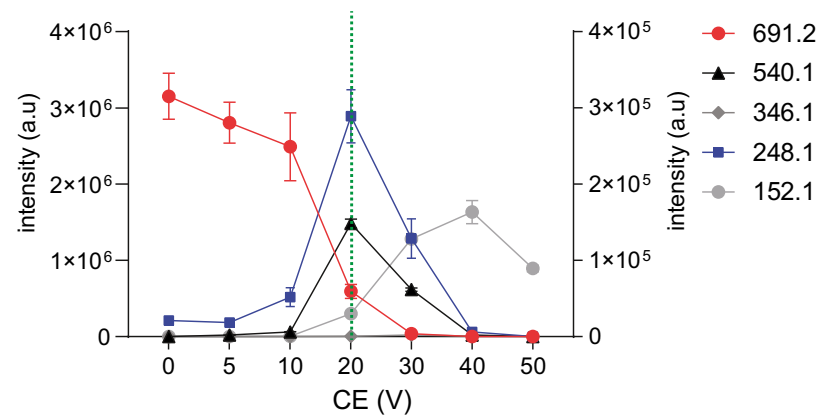

Fig. 3 Breakdown curves of selected product ions for CDNs. Precursor and product ion yields are plotted as a function of collision energy (CE) settings for 2'3' cGAMP (a), 3'3' cGAMP (b), with zoom in on specific ion products for $3^{\prime} 3^{\prime}$ cGAMP (c), c-di-AMP (d), with zoom in on specific

We then carried out the quantification of $2^{\prime} 3^{\prime}$ cGAMP in the killifish Nothobranchius furzeri. We examined compound levels in two tissues (liver and gut) of the laboratory strain GRZ-AD. Using CRISPR/Cas9 technology, we also
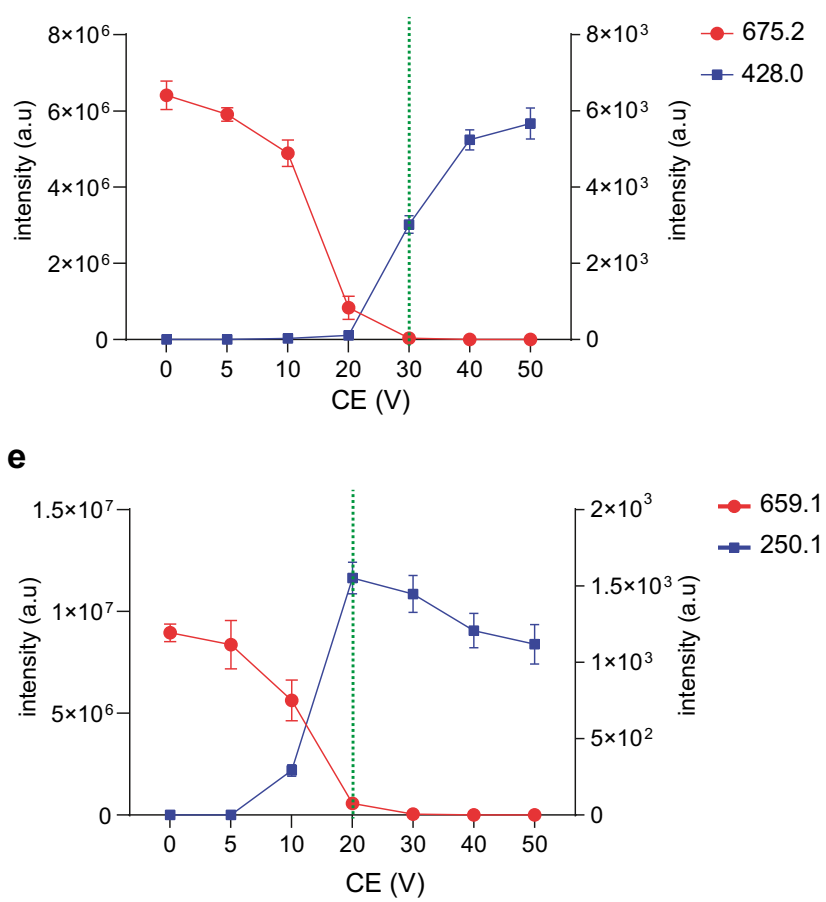

ion product for c-di-AMP (e), and c-di-GMP (f). Precursor ion intensity is plotted on the left $y$-axis, and product ion intensities are plotted on the right $y$-axis. Collision energies selected for the MRM method are indicated by the dotted green bar

generated a viable cGAS knock-out $\left(\mathrm{cGAS}^{-/}\right)$mutation, which disrupted the open reading frame and served as a negative control lacking the enzyme-producing endogenous $2^{\prime} 3^{\prime}$ cGAMP. As expected, the $2^{\prime} 3^{\prime}$ cGAMP peak was completely 
Table 1 Intraday interday error and recovery of cyclic dinucleotides

\begin{tabular}{|c|c|c|c|c|c|c|c|}
\hline \multirow[b]{2}{*}{$\begin{array}{l}\text { Compound } \\
\text { name }\end{array}$} & \multicolumn{3}{|l|}{ Intraday $n=5$} & \multicolumn{3}{|l|}{ Interday $n=5$} & \multirow[b]{2}{*}{ Recovery } \\
\hline & Average area & STD & $\%$ RSD & Average area & STD & $\%$ RSD & \\
\hline $2^{\prime} 3^{\prime}$ cGAMP & $4.45 \mathrm{E}+04$ & 2349.936 & 5.28 & $4.79 \mathrm{E}+03$ & 595.3594 & 12.41 & $91 \%$ \\
\hline 3'3' cGAMP & $5.32 \mathrm{E}+04$ & 5207.004 & 9.79 & $6.45 \mathrm{E}+03$ & 831.8047 & 12.90 & $83 \%$ \\
\hline c-di-AMP & $5.10 \mathrm{E}+04$ & 4676.97 & 9.16 & $8.07 \mathrm{E}+03$ & 764.1128 & 9.47 & $89 \%$ \\
\hline c-di-GMP & $2.95 \mathrm{E}+04$ & 1659.272 & 5.61 & $4.79 \mathrm{E}+03$ & 420.0636 & 8.77 & $85 \%$ \\
\hline
\end{tabular}

absent in the $\mathrm{cGAS}^{-/-}$knock-out line. In wild type, the MS spectra revealed the presence of a peak at the 1.71 min retention time similar to the standard peak of $2^{\prime} 3^{\prime}$ cGAMP (Fig. 4c, d). 2'3' cGAMP levels appeared slightly higher in the gut compared to the liver (Fig. 4e), though this difference did not reach significance.

\section{Discussion}

The present study illustrates a powerful new method to quantify cyclic dinucleotides in biological samples. Our method agrees well with previous work, which used similar chromatographic phases $[21,22]$. In addition, by deploying the specific CE-breakdown properties of the four cyclic dinucleotides, we identified for the first time new diagnostic fragments of the four CDNs, namely ion at $m / z 476.1$ for $2^{\prime} 3^{\prime} \mathrm{cGAMP}$, ion at $\mathrm{m} /$ $z 428.0$ for $3^{\prime} 3^{\prime}$ cGAMP, ion at $m / z 250.1$ for c-di-AMP, and ion at $\mathrm{m} / \mathrm{z} 248.1$ for c-di-GMP. Importantly, the transition selection and CE parameter optimization for each compound increased the sensitivity of our method compared to previous works by 1.4-2.5-fold [22].

In our studies, we observed that the CDNs show different profiles in the low and high collision energy ranges. Harrison et al. and others used a similar approach to obtain energyresolved fragmentation data from CID experiments of tripeptides [26-28]. We surmise that differences in the observed product ion intensity at higher collision energies reflect the different internal energy of the four molecules. Conceivably, the bond formed at $2^{\prime} 3^{\prime}$ or $3^{\prime} 5^{\prime}$ as well as the different hybridization properties of guanosine and adenosine moieties affect the energetic character and stability of the molecule. As shown by Green-Church and colleagues, the nucleobases adenine and guanine have slightly different proton affinities, and this property could affect the appearance of specific signals in the tandem mass spectra [29].

The fragmentation spectra of an ion are rich in information as it reflects the relative energy of the bonds present as well as the structure of both the precursor and product ions. Surprisingly, c-di-GMP did not produce as many fragments compared to other CDNs under our conditions. Conceivably, c-di-GMP might have slightly lower proton affinities, which could lead to the reduced formation of product ions. It is also possible that the two guanosine moieties increase the stability of c-di-GMP, rendering it less susceptible to CID compared to the other CDNs.

CDNs in metazoans function as endogenous second messengers that provoke multiple signaling cascades [30]. Though the enzymes for the synthesis of CDNs are evolutionarily conserved across species, the nucleotides used for the cyclization reaction and the cyclization bond differ somewhat between bacteria and vertebrates [2] (Fig. 4f).

Our quantification of CDNs in $E$. coli is in good agreement with previous work. It has been described previously that Gram-negative $E$. coli bacteria have higher levels of 3'3' cGAMP and c-di-GMP compared to c-di-AMP. Karaolis et al. describe a role of c-di-GMP in metal-reducing activity and host colonization [31]. Low levels of c-di-GMP are associated with flagella-based motility, and high levels promote biofilm production [4]. While bacterial synthesis of CDNs often occurs constitutively under normal physiological conditions and is essential for various aspects of growth and metabolism, they can also be regulated as part of the bacterial antiviral response [1].

In vertebrates, these bacterial produced CDNs can serve as pathogen-associated molecular patterns, which are able to
Table 2 Limits of detection, quantification, and calibration slopes of cyclic dinucleotides

\begin{tabular}{lllll}
\hline Compound name & LOQ $(\mathrm{ng} / \mathrm{mL})$ & LOD $(\mathrm{ng} / \mathrm{mL})$ & Calibration slopes & \\
\hline 2'3' cGAMP $^{\prime} 3^{\prime}$ & 0.17 & 0.46 & $y=156.95 x+285.34$ & $R^{2}=0.94$ \\
3'3' cGAMP $^{\prime}$ & 0.22 & 0.60 & $y=763.49 x+592.25$ & $R^{2}=0.95$ \\
c-di-AMP & 0.26 & 0.69 & $y=1390.5 x-21,342$ & $R^{2}=0.95$ \\
c-di-GMP & 0.19 & 0.50 & $y=1157.1 x-6467.4$ & $R^{2}=0.97$ \\
\hline
\end{tabular}


a
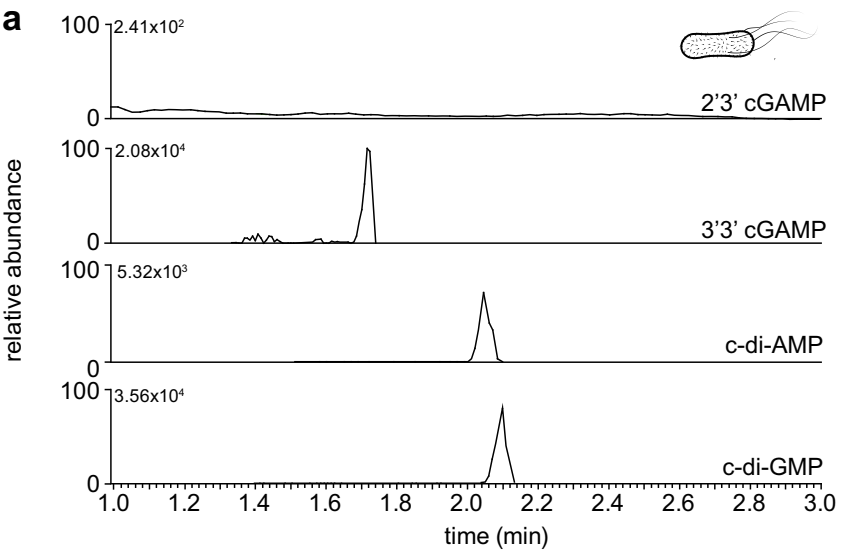

C

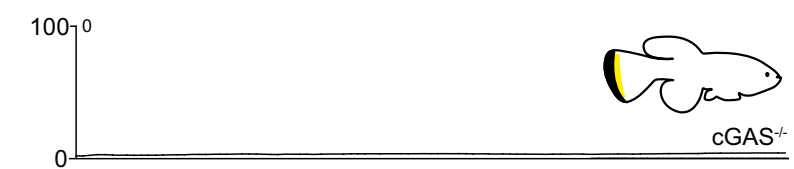

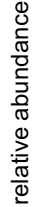

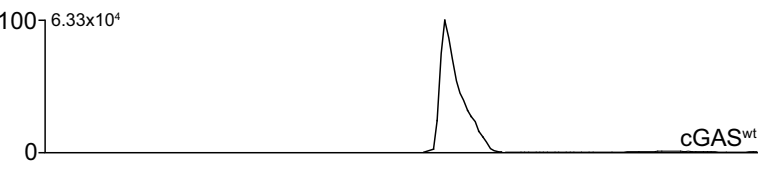

$100]^{8.21 \times 10^{6}}$

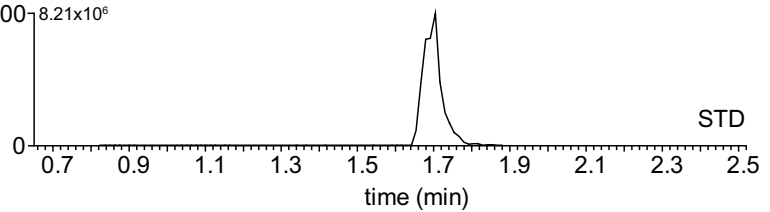

e

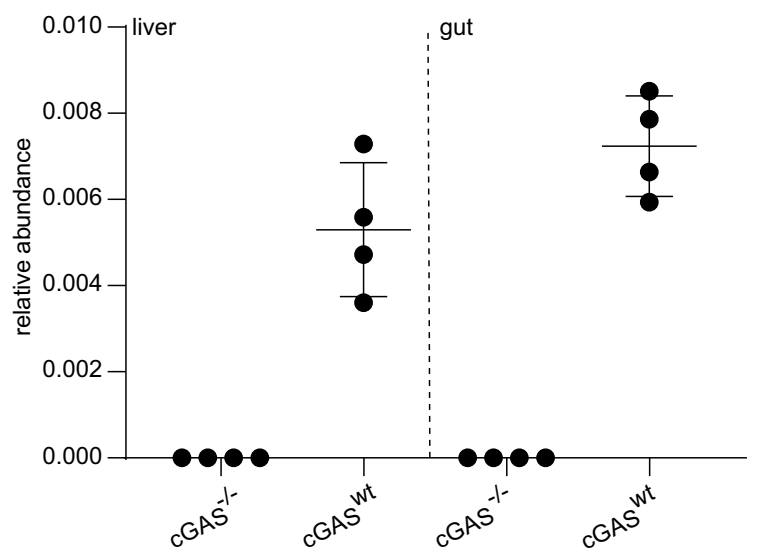

Fig. 4 Method validation and quantification of CDNs in vivo. a Quantification of CDNs in E. coli using the optimized LC-MS/MS parameters. b Relative abundance of CDNs is calculated by dividing the CDN peak area with the internal standard peak area and further normalized to protein levels. Quantification of $2^{\prime} 3^{\prime}$ cGAMP in liver (c) and gut (d) of killifish by LC-MS/MS. The first chromatogram is obtained from the mutant with non-functional cGAS $\left(\mathrm{cGAS}^{-1}\right)$, the second chromatogram from the laboratory wild-type killifish GRZ-Ad

directly activate STING and trigger innate immune defense upon infection [32]. In addition, cGAS can detect the inappropriate presence of DNA in the cytosol, and produce 2'3' cGAMP to activate STING, and b

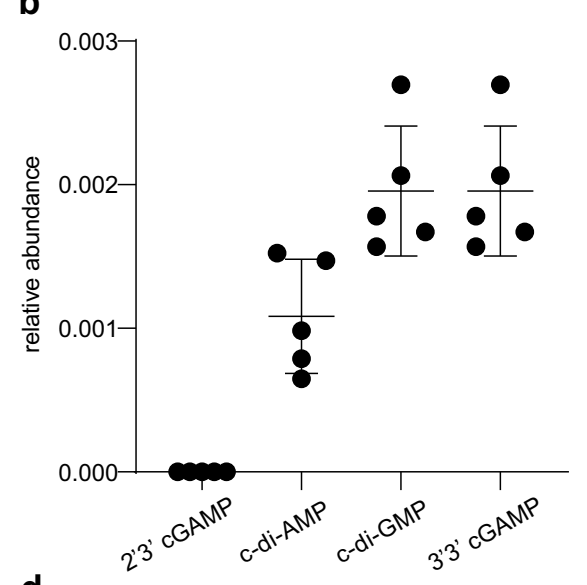

d
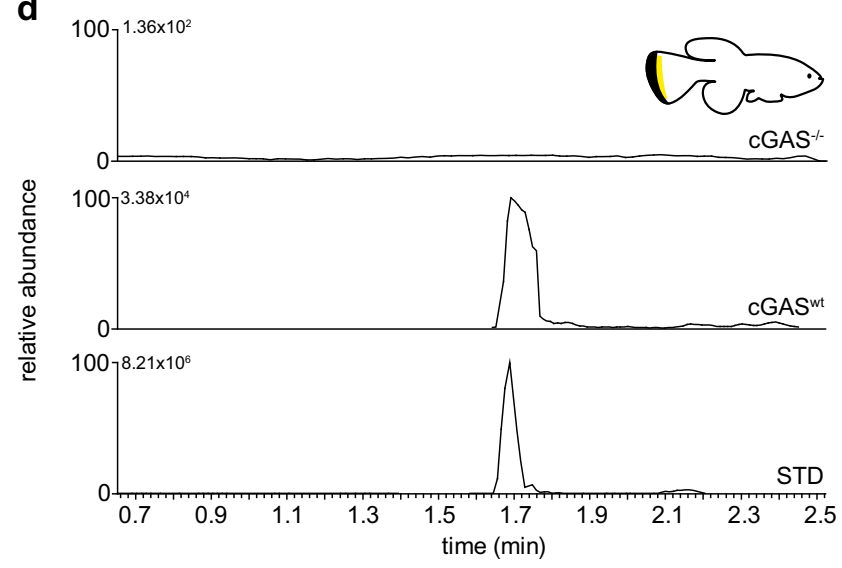

f

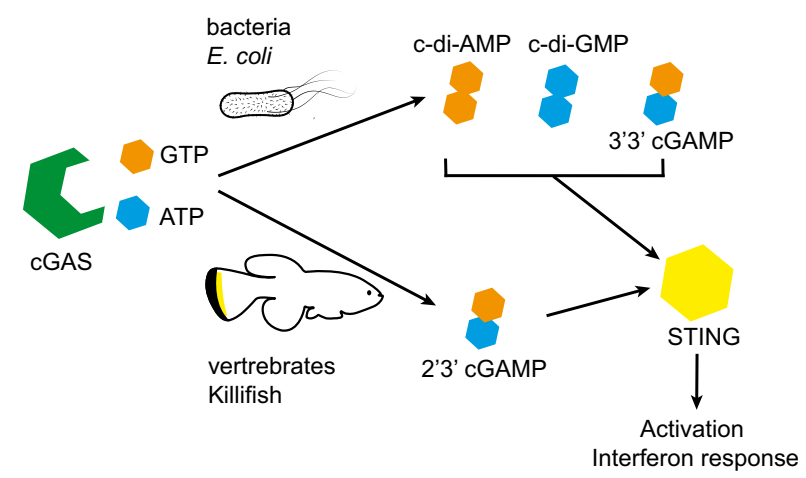

$\left(\mathrm{cGAS}^{\mathrm{wt}}\right)$. The bottom chromatogram corresponds to the 2'3' cGAMP standard. e Relative quantification of 2' $3^{\prime}$ cGAMP in the killifish tissues. Relative quantification is calculated by dividing the CDN peak area with the internal standard peak area and further normalized to protein levels. $\mathbf{f}$ Representation of the cGAS/Sting pathways in bacteria and vertebrates. Bacteria synthesize only c-di AMP, c-di-GMP, and 3'3' cGAMP, whereas vertebrates only synthesize $2{ }^{\prime} 3^{\prime}$ cGAMP

downstream effector pathways of interferon response and immune defense. Sources of cytosolic DNA can be exogenous, such as during viral infection, or endogenous, such as mitochondrial DNA (mtDNA), 
micronuclei, and chromosomal fragments that arise under conditions of genome instability and aging [1, 33-35], leading to chronic inflammation and senescence [36]. The ability to accurately measure these CDNs should enable a clearer understanding of their dynamics in vivo in various contexts.

To evaluate the $2^{\prime} 3^{\prime}$ cGAMP concentration in vertebrates, we used the African turquoise killifish Nothobranchius furzeri as a model system. The inbred laboratory wild-type strain of this species, GRZ-AD, lives approximately 6 to 7 months, making it among the shortest-lived vertebrates kept in captivity $[23,37]$. Nothobranchius is readily amenable to genetic manipulation, since transgenesis and crispr-mediated genome engineering are nearly as facile as other model organisms [38, 39]. We report here for the first time the generation of a $\mathrm{cGAS}^{-/-}$knock-out line in the killifish, demonstrating conservation of its biochemical activity in vivo. Using our new method, we observed that 2' $3^{\prime}$ cGAMP is absent from the liver and gut tissues of $\mathrm{cGAS}^{-/}$knock-out fish, providing clear genetic evidence that cGAS is the sole enzyme synthesizing $2^{\prime} 3^{\prime}$ cGAMP in this organism.

To date, 2'3' cGAMP has been quantified mostly in in vitro cell culture models and only a handful of groups have used methods of detection from whole animal tissues [30]. These methods require more starting material, and have multiple extraction and enrichment steps that are quite labor intensive. By comparison, we developed a relatively simple and efficient method for the quantification of the four known natural CDNs from vertebrate tissues as well as bacterial cells [40], allowing a scale-down of sample preparation and greater sensitivity. Further, our procedure does not require heat treatment, which might affect the stability of CDNs [41]. With this method, future studies can illuminate CDN dynamics in various tissues and organisms, and thus help elucidate their physiological impact in organismal health.

\section{Conclusion}

In the current study, we established a highly sensitive mass spectrometry-based method for the quantification of CDNs in vivo. Using product ion scans in combination with CEbreakage curves, we unraveled the mass spectrometric behavior of four biological relevant CDNs. This work can pave the way to further investigate the diverse energy states and stability of CDNs.

Our studies should greatly facilitate the measurement of $\mathrm{CDN}$ levels in different model organisms as well as in human tissues. In particular, because CDNs are key factors in the immune response, their accurate measurement may help reveal fundamental aspects of immune signaling and immunosenescence. Finally, in the future, it will be interesting to further characterize CDN functions and their physiological impact using the cGAS knock-out mutants in the killifish.

Supplementary Information The online version contains supplementary material available at https://doi.org/10.1007/s00216-021-03628-6.

Acknowledgements We thank the Fish Caretakers of the Max Planck Institute for Biology of Ageing.

Funding Open Access funding enabled and organized by Projekt DEAL. This work was supported by the Max Planck Society.

\section{Declarations}

Research involving human participants and/or animals Fish husbandry was performed in the fish facility of the MPI-Age (Permit Nr. 576.1.36.6.G12/18 Be). The use of animals in these trials complied with national legislation in accordance with the ethical standards of the Lanuv (Landesamt für Natur, Umwelt und Verbraucherschutz NordrheinWestfalen) and the Animal Welfare Body of the MPI-Age.

Conflict of interest The authors declare no competing interests.

Open Access This article is licensed under a Creative Commons Attribution 4.0 International License, which permits use, sharing, adaptation, distribution and reproduction in any medium or format, as long as you give appropriate credit to the original author(s) and the source, provide a link to the Creative Commons licence, and indicate if changes were made. The images or other third party material in this article are included in the article's Creative Commons licence, unless indicated otherwise in a credit line to the material. If material is not included in the article's Creative Commons licence and your intended use is not permitted by statutory regulation or exceeds the permitted use, you will need to obtain permission directly from the copyright holder. To view a copy of this licence, visit http://creativecommons.org/licenses/by/4.0/.

\section{References}

1. Cohen D, Melamed S, Millman A, Shulman G, OppenheimerShaanan Y, Kacen A, et al. Cyclic GMP-AMP signalling protects bacteria against viral infection. Nature. 2019;574(7780):691-5.

2. Whiteley AT, Eaglesham JB, de Oliveira Mann CC, Morehouse BR, Lowey B, Nieminen EA, et al. Bacterial cGAS-like enzymes synthesize diverse nucleotide signals. Nature. 2019;567(7747): 194-9.

3. Jiang H, Xue X, Panda S, Kawale A, Hooy RM, Liang F, et al. Chromatin-bound cGAS is an inhibitor of DNA repair and hence accelerates genome destabilization and cell death. EMBO J. 2019;38(21):e102718.

4. Ha DG, O'Toole GA. c-di-GMP and its effects on biofilm formation and dispersion: a Pseudomonas Aeruginosa review. Microbiology spectrum. 2015;3(2):Mb-0003-2014.

5. Opoku-Temeng C, Sintim HO. Targeting c-di-GMP signaling, biofilm formation, and bacterial motility with small molecules. Methods in molecular biology (Clifton, NJ). 2017;1657:419-30. 
6. Cimdins A, Simm R, Li F, Lüthje P, Thorell K, Sjöling Å, et al. Alterations of c-di-GMP turnover proteins modulate semiconstitutive rdar biofilm formation in commensal and uropathogenic Escherichia coli. MicrobiologyOpen. 2017;6(5).

7. Wu J, Sun L, Chen X, Du F, Shi H, Chen C, et al. Cyclic GMPAMP is an endogenous second messenger in innate immune signaling by cytosolic DNA. Science (New York, NY). 2013;339(6121):826-30.

8. Wu X, Wu FH, Wang X, Wang L, Siedow JN, Zhang W, et al. Molecular evolutionary and structural analysis of the cytosolic DNA sensor cGAS and STING. Nucleic Acids Res. 2014;42(13):8243-57.

9. Ablasser A, Goldeck M, Cavlar T, Deimling T, Witte G, Röhl I, et al. cGAS produces a 2'-5'-linked cyclic dinucleotide second messenger that activates STING. Nature. 2013;498(7454):380-4.

10. Ishikawa H, Ma Z, Barber GN. STING regulates intracellular DNA-mediated, type I interferon-dependent innate immunity. Nature. 2009;461(7265):788-92.

11. Lahaye X, Satoh T, Gentili M, Cerboni S, Conrad C, Hurbain I, et al. The capsids of HIV-1 and HIV-2 determine immune detection of the viral cDNA by the innate sensor cGAS in dendritic cells. Immunity. 2013;39(6):1132-42.

12. Berthelot JM, Lioté F, Maugars Y, Sibilia J. Lymphocyte changes in severe COVID-19: delayed over-activation of STING? Front Immunol. 2020;11:607069.

13. Hopfner KP, Hornung V. Molecular mechanisms and cellular functions of cGAS-STING signalling. Nat Rev Mol Cell Biol. 2020;21(9):501-21.

14. Chen Q, Sun L, Chen ZJ. Regulation and function of the cGASSTING pathway of cytosolic DNA sensing. Nat Immunol. 2016;17(10):1142-9.

15. Motwani M, Pesiridis S, Fitzgerald KA. DNA sensing by the cGAS-STING pathway in health and disease. Nat Rev Genet. 2019;20(11):657-74.

16. Basit A, Cho MG, Kim EY, Kwon D, Kang SJ, Lee JH. The cGAS/STING/TBK1/IRF3 innate immunity pathway maintains chromosomal stability through regulation of p21 levels. Exp Mol Med. 2020;52(4):643-57.

17. Li L, Yin Q, Kuss P, Maliga Z, Millán JL, Wu H, et al. Hydrolysis of 2'3'-cGAMP by ENPP1 and design of nonhydrolyzable analogs. Nat Chem Biol. 2014;10(12):1043-8.

18. Miyakawa S, Okui T, Shiraishi T, Yoshihara T, Hirayama M, Satomi Y, et al. Development of novel highly sensitive methods to detect endogenous cGAMP in cells and tissue. J Immunol Methods. 2020;480:112751.

19. Li X, Shu C, Yi G, Chaton CT, Shelton CL, Diao J, et al. Cyclic GMP-AMP synthase is activated by double-stranded DNA-induced oligomerization. Immunity. 2013;39(6):1019-31.

20. Bose D, Su Y, Marcus A, Raulet DH, Hammond MC. An RNAbased fluorescent biosensor for high-throughput analysis of the cGAS-cGAMP-STING pathway. Cell chemical biology. 2016;23(12):1539-49.

21. Lorenzetti R, Lilla S, Donato JL, de Nucci G. Simultaneous quantification of GMP, AMP, cyclic GMP and cyclic AMP by liquid chromatography coupled to tandem mass spectrometry. J Chromatogr B Anal Technol Biomed Life Sci. 2007;859(1):37-41.

22. Paijo J, Kaever V, Kalinke U. cGAMP quantification in virusinfected human monocyte-derived cells by HPLC-coupled tandem mass spectrometry. Methods in molecular biology (Clifton, NJ). 2017;1656:153-66.

23. $\mathrm{Hu} \mathrm{CK}$, Brunet A. The African turquoise killifish: a research organism to study vertebrate aging and diapause. Aging Cell. 2018;17(3):e12757.

24. Annibal A, Tam H, Latza C, Antebi A. Comparison of ESI-MS/MS and APCI-MS methods for the quantification of folic acid analogs in C. elegans. Journal of mass spectrometry : JMS. 2019;54(4):316-27.

25. Dabrowski R, Ripa R, Latza C, Annibal A, Antebi A. Optimization of mass spectrometry settings for steroidomic analysis in young and old killifish. Anal Bioanal Chem. 2020;412(17):4089-99.

26. Harrison AG. Energy-resolved mass spectrometry: a comparison of quadrupole cell and cone-voltage collision-induced dissociation. Rapid communications in mass spectrometry : RCM. 1999;13(16):1663-70.

27. Zhang P, Chan W, Ang IL, Wei R, Lam MMT, Lei KMK, et al. Revisiting fragmentation reactions of protonated $\alpha$-amino acids by high-resolution electrospray ionization tandem mass spectrometry with collision-induced dissociation. Sci Rep. 2019;9(1):6453.

28. Dookeran NN, Yalcin T, Harrison AG. Fragmentation reactions of protonated $\alpha$-amino acids. J Mass Spectrom. 1996;31(5):500-8.

29. Green-Church KB, Limbach PA. Mononucleotide gas-phase proton affinities as determined by the kinetic method. J Am Soc Mass Spectrom. 2000;11(1):24-32.

30. Gao P, Ascano M, Wu Y, Barchet W, Gaffney BL, Zillinger T, et al. Cyclic $\left[\mathrm{G}\left(2^{\prime}, 5^{\prime}\right) \mathrm{pA}\left(3^{\prime}, 5^{\prime}\right) \mathrm{p}\right]$ is the metazoan second messenger produced by DNA-activated cyclic GMP-AMP synthase. Cell. 2013;153(5):1094-107.

31. Karaolis DK, Rashid MH, Chythanya R, Luo W, Hyodo M, Hayakawa Y. C-di-GMP (3'-5'-cyclic diguanylic acid) inhibits Staphylococcus aureus cell-cell interactions and biofilm formation. Antimicrob Agents Chemother. 2005;49(3):1029-38.

32. Diner EJ, Burdette DL, Wilson SC, Monroe KM, Kellenberger CA, Hyodo M, et al. The innate immune DNA sensor cGAS produces a noncanonical cyclic dinucleotide that activates human STING. Cell Rep. 2013;3(5):1355-61.

33. Huang LS, Hong $\mathrm{Z}, \mathrm{Wu} \mathrm{W}$, Xiong $\mathrm{S}$, Zhong $\mathrm{M}$, Gao X, et al. mtDNA activates cGAS signaling and suppresses the YAPMediated Endothelial Cell Proliferation Program to promote inflammatory injury. Immunity. 2020;52(3):475-86.e5.

34. Mackenzie KJ, Carroll P, Martin CA, Murina O, Fluteau A, Simpson DJ, et al. cGAS surveillance of micronuclei links genome instability to innate immunity. Nature. 2017;548(7668):461-5.

35. Hong C, Tijhuis AE, Foijer F. The cGAS paradox: contrasting roles for cGAS-STING pathway in chromosomal instability. Cells. 2019;8(10).

36. Li T, Chen ZJ. The cGAS-cGAMP-STING pathway connects DNA damage to inflammation, senescence, and cancer. J Exp Med. 2018;215(5):1287-99.

37. Terzibasi Tozzini E, Cellerino A. Nothobranchius annual killifishes. EvoDevo. 2020;11(1):25.

38. Dolfi L, Ripa R, Antebi A, Valenzano DR, Cellerino A. Cell cycle dynamics during diapause entry and exit in an annual killifish revealed by FUCCI technology. EvoDevo. 2019;10:29.

39. Ripa R, Dolfi L, Terrigno M, Pandolfini L, Savino A, Arcucci V, et al. MicroRNA miR-29 controls a compensatory response to limit neuronal iron accumulation during adult life and aging. BMC Biol. 2017;15(1):9.

40. Burhenne H, Kaever V. Quantification of cyclic dinucleotides by reversed-phase LC-MS/MS. Methods in molecular biology (Clifton, NJ). 2013;1016:27-37.

41. Spangler C, Böhm A, Jenal U, Seifert R, Kaever V. A liquid chromatography-coupled tandem mass spectrometry method for quantitation of cyclic di-guanosine monophosphate. J Microbiol Methods. 2010;81(3):226-31.

Publisher's note Springer Nature remains neutral with regard to jurisdictional claims in published maps and institutional affiliations. 


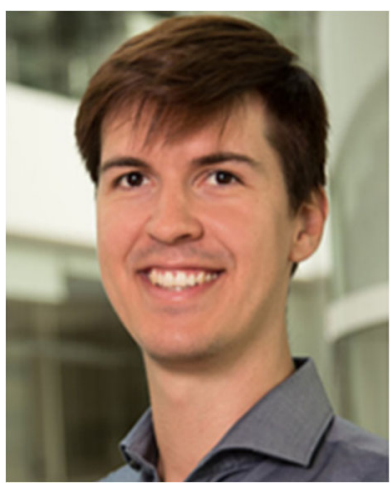

Andrea Annibal holds a $\mathrm{PhD}$ in analytical chemistry and is a postdoctoral researcher in the Department of Molecular Genetics of Ageing at the Max Planck Institute for Biology of Ageing. His research interests comprise the optimization of new analytical methods using mass spectrometry and the development of a new untargeted method for metabolomics.

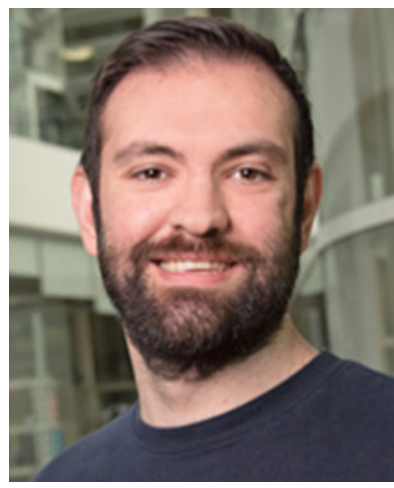

Roberto Ripa obtained his $\mathrm{PhD}$ in neurobiology and is a postdoctoral researcher within the Department of Molecular Genetics of Ageing at the Max Planck Institute for Biology of Ageing. His research interests focus on the interplay between metabolism and inflammation during aging in the African turquoise killifish Nothobranchius furzeri.

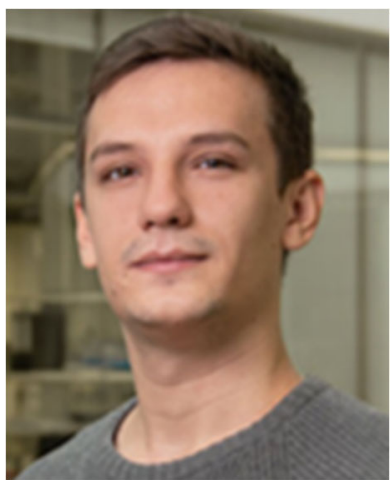

Eugen Ballhysa is a $\mathrm{PhD}$ student at the Cologne Graduate School of Ageing Research, at the Max Planck Institute for Biology of Ageing. His current research interests include deciphering the interplay between nucleic acid surveillance and vertebrate health span as well as investigating the causes of inflammaging.

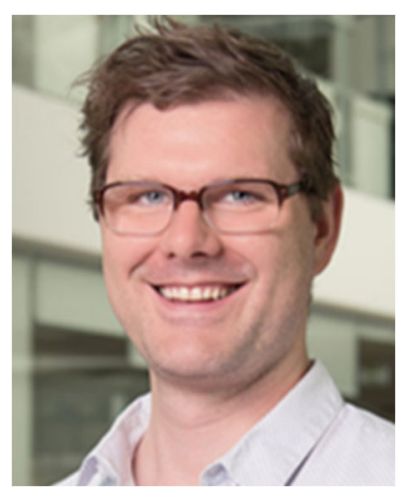

Christian Latza obtained his diploma in biology and works using mass spectrometry in the Department of Molecular Genetics of Ageing at the Max Planck Institute for Biology of Ageing.

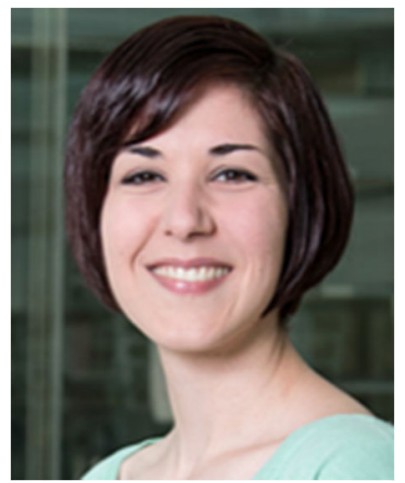

Nadine Hochhard works as a technical assistant in the Department of Molecular Genetics of Ageing at the Max Planck Institute for Biology of Ageing.

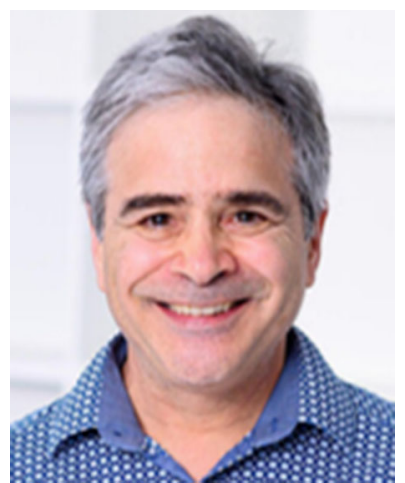

Adam Antebi is Managing Director of the Max Planck Institute for Biology of Ageing, Cologne, Germany. The goal of his research is to unravel regulatory mechanisms that govern the aging process, using the nematode Caenorhabditis elegans, the African turquoise killifish Nothobranchius furzeri, and human cells as models. 